\title{
Cerebellar Papillary Meningioma
}

National Cancer Institute

\section{Source}

National Cancer Institute. Cerebellar Papillary Meningioma. NCI Thesaurus. Code C5270.

A papillary meningioma that affects the cerebellum. 